\title{
Comparison of the Effectiveness of Resilience Training and Emotion Regulation on Psychological Well-being and Self- efficacy of Firefighters
}

\author{
Niloofar Sharifi $^{1 *}$, Sajjad Basharpoor ${ }^{1}(\mathbb{D})$, Mohammad Narimani1(D) \\ 1 Department of Psychology, School of Educational Sciences and Psychology, University of Mohaghegh \\ Ardabili, Ardabil, Iran
}

\begin{abstract}
*Corresponding author:
Niloofar Sharifi, Department of

Psychology, School of Educational

Sciences and Psychology, University

of Mohaghegh Ardabili, Ardabil, Iran

Tel: 09380437061

Email: niloofarsharifi266@gmail.com
\end{abstract}

Received: 15 Jul. 2020

Accepted: 25 Mar. 2021

ePublished: 01 Nov. 2021

\begin{abstract}
Background and Objective: Firefighters are at risk of mental health deterioration due to their stressful jobs, and psychological skills training plays a positive role in this regard. This study aimed to compare the effectiveness of resiliency training and emotion-regulation training on the psychological well-being and self-efficacy of firefighters.

Materials and Methods: This was an experimental study with a multi-group pretest-posttest control group design. In autumn 2018, forty-five Ardabil firefighters selected by simple random sampling were randomly assigned into three groups of resiliency-training $(n=15)$, emotion-regulation-training $(n=15)$, and control $(n=15)$. All three groups completed the demographic questionnaire, Ryff's Psychological Well-Being Scale, and General Self-Efficacy Scale (Scherer et al., 1982) in the pre-test and post-test stages. The collected data were analysed using SPSS software (version16) through the analysis of covariance and Bonferroni post hoc test.

Results: Resiliency training and emotion-regulation had a significant effect on one's psychological well-being and self-efficacy. The results of the post hoc test also indicated that the effectiveness of resiliency training and emotion-regulation on one's self-efficacy was significantly different and resiliency training was more effective than emotion-regulation training.

Conclusions: Resiliency training and emotion-regulation training were effective on the psychological well-being and self-efficacy of firefighters.
\end{abstract}

Keywords: Emotion-regulation training, Firefighters, Resiliency-training important psychological skills.

Resilience is an ability that is effective in dealing with stress in adverse situations. Masten's resilience training teaches one the skills needed to adapt and to return to the precrisis status [7].

Behzadpour et.al [8] observed that resiliency training is effective on the psychological wellbeing of the individual. The results of a study conducted by Momeni et. al [9] revealed that resiliency training had a significant effect on reducing anxiety symptoms in adolescents with heart disease. Martin et al. [10] concluded that resiliency training can be effective in increasing resilience and reducing burnouts in nurses.

Emotion-regulation training is one of the appropriate training for those who are unable to regulate their emotions in face of stressful situations. Therefore, emotion regulation plays an important role in the psychological wellbeing of each person [11].

Emotion-regulation training [12] includes the 
reduction and control of negative emotions and performance. Emotion regulation is a necessary and important factor for adaptive functioning. The use of maladaptive strategies leads to negative outcomes, such as a low level of wellbeing and physical illness [13]. The findings of the study performed by Moradi Kia et al. [14] indicated that emotion-regulation training is effective in improving the psychological wellbeing of mothers. The ethical research of Yazdinejad et al. [15] showed that emotionregulation training had a significant effect on increasing consumer self-efficacy and psychological well-being. The results of a study carried out by Cameron et al. [16] showed that emotion-regulation training has been effective in improving the psychological resilience and wellbeing of adults.

Resilience and emotion regulation training can be effective for firefighters due to the fact that firefighters are regularly exposed to occupational stressors that can affect their mental health. It is worth mentioning that resilience training and emotion regulation training protocols have common elements and both emphasize on selfregulating abilities such as self-awareness, selfefficacy, cognition, and control of emotions. However, resilience training emphasizes on mind control and aims to improve personality and mental characteristics. Therefore, when one is faced with problems, resilience training can help the person control his/her thoughts and practice self-control. However, emotion regulation training has its emphasis on recognizing emotions and their effects on human physiology and behavior. It helps the individuals to be able to control themselves in adverse situations and have a proper performance through emotion regulation training.

The results showed the effectiveness of resilience and emotion-regulation training on the reduction of anxiety, stress, and depression in different groups, including pregnant women, cardiovascular patients, and nurses; however, this training has not been studied on firefighters. On the other hand, these two educational programs have not been compared so far to determine which one is more effective.

\section{Objectives}

Therefore, considering the role of resilience training and emotion regulation in the improvement of mental health and prevention, treatment, and control of the damages caused by stressful jobs, this study aimed to compare resilience training and emotion regulation training in psychological well-being and selfefficacy of firefighters.

\section{Materials and Methods}

Study population, Sample group, and Sampling method

This experimental randomized controlled trial had a multi-group pretest-posttest design and a control group. The statistical population of this study included the total number of employees working in the fire department of Ardabil in October 2018. The statistical population consisted of 210 individuals, of whom 45 firefighters from Ardabil were randomly selected and assigned to three groups of resilience skills training $(n=15)$, emotion regulation training $(\mathrm{n}=15)$, and the control group $(n=15)$. The age range of participants was between 30 and 45 years in this study. The inclusion criteria included an employment history of at least three years and lack of mental disorder. The absence of more than three sessions in training sessions, unwillingness to participate in the sessions, and the occurrence of special occasions, such as marriage, death of loved ones, and specific illnesses were the exclusion criteria in this study.

Research tools

Ryff's Psychological Well-being Scale

This is an 18-item self-report scale that evaluates and examines the person's psychological well-being from different dimensions (i.e., independence, mastery of the environment, personal growth, positive communication with others, purposefulness in life, and selfacceptance). This scale is scored based on a 6points Likert scale. However, it should be noted that items $1,3,4,5,9,10,13$, and 17 on this scale are scored in reverse. The results of singlegroup confirmatory factor analysis in the study conducted by Khanjani et al. [17] showed that in the whole sample and in both genders, a sixitem model of this scale (self-acceptance, environmental mastery, positive relationship with others, the possession of objectives, personal growth, and independence) had a good fit. The internal consistency of this scale using Cronbach's alpha in 6 items of self-acceptance, environmental dominance, positive relationship with others, possession of a purpose in life, personal growth, and independence, was determined at $0.51,0.76,0.75,0.52,0.73,0.72$, respectively. Moreover, Cronbach's alpha of the whole scale was obtained at 0.71 . 
General self-efficacy Scale

This scale is a self-reporting tool developed by Sherer et al. [18]. The original version of the scale consisted of 36 items. The creators kept items that had a load of 0.40 on each of the social and public factors. Accordingly, 13 items that did not match this requirement were removed and the scale was reduced to 23 items. It should be noted that 17 out of these 23 questions measure general self-efficacy with a mean $\pm S D$ of $99.57 \pm 08$. According to the study performed by Keramati and Shahr-Arai [19], the reliability of the test in a group of 100 people was 0.61, which was significant at the 0.05 level. The validity coefficient of the test was obtained using the Spearman-Brown formula with a length value of 0.76 and an unequal length value of 0.76 and by the Guttman split half method coefficient (0.76). Total homogeneity of materials was reported to be 0.79 and its validity was determined at 0.85 using Cronbach's alpha method.

\section{Educational interventions}

\section{Procedure}

The study protocol was approved by the Ethics Committee of Mohaghegh Ardabili University (IR.ARUMS.REC.1396.112). The study participants included 45 employees from Ardabil Fire Department and randomly divided them into three groups (two experimental groups and one control group). Initially, all three groups responded to psychological well-being and self-efficacy questionnaires. Afterward, the first and second experimental groups underwent resilience training and emotion regulation training, respectively. However, the control group did not receive any training. Eventually, all three groups responded to questionnaires and the results were evaluated.

\section{Data analysis}

The statistical data were analyzed using SPSS software through multivariate analysis of covariance and Bonferroni post hoc test. Descriptive data were presented as mean and standard deviation.

\section{Results}

Table 2 presents the mean and standard deviation of the pre-test and post-test scores of the psychological well-being and self-efficacy in the three participating groups. The box test was used before the multivariate variance analysis parametric test to examine its assumptions. The homogeneity condition of the variance matrices has been properly observed according to the results of the box test $(\mathrm{P}=0.16, \mathrm{BOX}=18.62)$. Table 3 presents the increased alpha of Benferoni (0.025) resilience training and emotion regulation on psychological well-being and self-efficacy in a combined variable with $=$ 0.61 or Partial, Lambda Wilkes $=0.14$, / 7519 $=(6,74) \mathrm{F}$ had a significant effect $(\mathrm{P}<0.001)$.

Based on the data resented in Table 4, resilience, and emotion regulation training had a significant effect on psychological well-being $(\mathrm{F}=15.41)$ and self-efficacy of firefighters $(\mathrm{F}=28.50 ; \mathrm{P}<0.001)$.

Table1. Content of the education and treatment sessions

\begin{tabular}{|c|c|c|}
\hline Sessions & Resilience-training & Emotion-regulation-training \\
\hline 1 & $\begin{array}{l}\text { Introducing people, Explaining the process of sessions, } \\
\text { Explaining resilience, and pre-test. }\end{array}$ & $\begin{array}{l}\text { Introducing people, Explaining the process of } \\
\text { sessions, Explanting emotion regulation, and pre-test. }\end{array}$ \\
\hline 2 & Teaching self-esteem and a sense of worth. & Training positive emotions \\
\hline 3 & $\begin{array}{l}\text { Linking training, Improving people's ability to communicate } \\
\text { and socialize }\end{array}$ & Training on awareness about negative emotions \\
\hline 4 & $\begin{array}{l}\text { Defining a goal, Setting a goal, Teaching how to achieve } \\
\text { the set goals. }\end{array}$ & Teaching on acceptance of positive emotions. \\
\hline 5 & Teaching and defining self-efficacy & Learning to accept negative emotions \\
\hline 6 & $\begin{array}{c}\text { Teaching problem-solving steps, Achieving self-efficacy to } \\
\text { solve problems. }\end{array}$ & Training on emotional expression. \\
\hline 7 & Educating about responsibility & Training to re-evaluating emotions \\
\hline 8 & $\begin{array}{l}\text { Teaching stress management methods, Summarizing } \\
\text { sessions, Scheduling sessions for the post-test. }\end{array}$ & $\begin{array}{l}\text { Training to re-evaluate the expressed emotion, } \\
\text { Summarizing sessions, Scheduling sessions for the post- } \\
\text { test. }\end{array}$ \\
\hline
\end{tabular}

Table 2. Means and standard deviations of pre-test and post-test overall scores of psychological well-being and self-efficacy in three participating groups

\begin{tabular}{ccccccc}
\hline \multicolumn{2}{c}{ Resilience } & \multicolumn{2}{c}{ Emotion regulation } & \multicolumn{2}{c}{ Control group } & \\
\hline $\mathrm{D}$ & $\mathrm{M}$ & $\mathrm{SD}$ & $\mathrm{M}$ & $\mathrm{SD}$ & $\mathrm{M}$ & well-being \\
5.12 & 70.37 & 4.22 & 71.06 & 6.23 & 70.45 & self-efficacy \\
3.21 & 43.93 & 2.49 & 46.93 & 4.22 & 45.40 & well-being \\
7.91 & 69.33 & 5.49 & 841 & 5.91 & 81.20 & Pre-test \\
4.01 & 43.66 & 3.77 & 49.40 & 2.37 & 3.73 & self-efficacy \\
\hline
\end{tabular}


The results of the follow-up test showed that the effectiveness of resilience and emotion regulation training on self-efficacy was significantly different
$(\mathrm{P}<0.001)$ and resilience training was more effective than emotion regulation training on the improvement of one's self-efficacy (Table 5).

Table3. Test of the combined effect of resilience training and emotion regulation on mental well-being and self-efficacy

\begin{tabular}{llllll}
\hline 0.61 & 0.000 & 74.00 & 6.00 & 19.75 & 0.14 \\
\hline
\end{tabular}

Table 4. Results of single-variable covariance analysis, resilience-training, and emotion-regulation on mental well-being and selfefficacy

\begin{tabular}{lcccrrr}
\hline Variable & SS & Df & MS & F & P \\
\hline Well-being & 326.79 & 1 & 326.79 & 9.87 & 0.003 \\
Self-efficacy & 87.82 & 1 & 87.82 & 0.26 & 0.007 \\
Well-being & 1019.78 & 2 & 509.89 & 15.41 & 0.175 \\
Self-efficacy & 605.58 & 2 & 302.791 & 21.50 & 0.441 \\
\hline
\end{tabular}

Table 5. Benfreoni's test results of comparison between resilience-training and post-test emotion-regulation of dependent variables

\begin{tabular}{|c|c|c|c|c|c|}
\hline \multirow[t]{2}{*}{ Variable } & & \multicolumn{2}{|c|}{ Emotion-regulation } & \multicolumn{2}{|c|}{ Control } \\
\hline & & $(\mathrm{I}-\mathrm{J})$ & $\mathrm{P}$ & $(\mathrm{I}-\mathrm{J})$ & $\mathrm{P}$ \\
\hline Well-being & Resilience & 1.56 & 0.001 & 11.62 & 0.001 \\
\hline & Emotion-regulation & - & - & 10.06 & 0.001 \\
\hline Self-efficacy & Resilience & 4.95 & 0.001 & 9.45 & 0.001 \\
\hline & Emotion-regulation & - & - & 4.49 & 0.004 \\
\hline
\end{tabular}

\section{Discussion}

This study aimed to determine the effectiveness of resilience and emotion regulation training on the psychological well-being and self-efficacy of firefighters and compare the results. The results of the comparison showed that resilience training had a positive effect on the overall score of psychological well-being. These results are similar to those obtained in studies carried out by Dousti et al. [20] and Behzadpour et al. [8] which showed that resilience training is effective in increasing the psychological well-being of the person. According to Wissing et al. [21], psychological well-being is multifaceted and includes areas of emotion, cognition, behavior, and interpersonal relationships. The results also showed that resilience training is effective in increasing the overall score of selfefficacy. From Bandura's perspective, self-efficiency affects the quality of human performance in different ways [22]. One session of resiliencetraining sessions was dedicated to teaching selfefficacy. During the session, the concept of selfefficacy was discussed, and exercises were taught to strengthen self-efficacy. The participants could change their thoughts about themselves, their characteristics, and skills during the session which ultimately led to the increase of their self-efficacy.

The effectiveness of emotion regulation training and resilience training was evaluated on the psychological well-being of the participants and the results were compared. The results of the comparison of the score means between experiment and control groups showed that emotion regulation training had a positive effect on the overall score of psychological well-being and promotes mental well-being. These findings are consistent with those of MoradiKia et al. [14] and Mehrabi Pari et al. [6] who showed that emotion regulation training is effective in promoting one's psychological well-being. The results obtained in the study performed by Ryff [23] revealed that psychological well-being goes beyond the absence of disease and included positive self-confidence, independence, and positive relationships with others. Similarly, Kleinner [24] stated that psychological wellbeing includes positive emotions, self-excellence, life satisfaction, hope, love, and courage. The results of the above studies and exercises carried out during the emotional training sessions, such as examination of relationships with others, identification of individuals, and preparation of a list of positive activities confirm the improvement of psychological well-being as a result of these training.

The results also showed that emotion regulation training is effective in increasing the overall score of self-efficacy. These results are directly in line with the findings of Foolad-Chang et al. [25] and the ethical findings of Yazdinejad et al. [15] and indirectly in line with the results obtained in the study conducted by Choopan et al. [26] which showed that emotion regulation training increases self-efficacy. Studies have shown that human behavior is more influenced by external factors than what we have thought so far. In fact, reciprocal determinism implies that behavior, environment, and individuals interact and that this tripartite interaction determines behavior [22]. The total amount of training provided to firefighters during the emotion regulation training sessions can all be 
effective in increasing their self-efficacy. The cognitive exercises offered can change and modify people's beliefs about themselves and their abilities and increase their sense of self-efficacy. Moreover, learning skills and the way one should identify and cope with his/her emotions correctly can lead to increased self-efficacy.

\section{Conclusions}

The results of the comparison between the effectiveness of resiliency- training, and emotion regulation on firefighters' psychological well-being indicated that there is no significant difference between the effectiveness of resilience training and emotion-regulation training on firefighters' psychological well-being. The explanation for the same effectiveness of two methods of resiliencetraining and emotion-regulation training is that resilience-training improves self-efficiency with such exercises as self-esteem training that create and maintain emotion and positive cognition, as well as exercises that help to create proper communication, and emotion-regulation training improves selfefficiency through the examination of one's relationships with others and identification of individual and interpersonal situations.

Moreover, the comparison of the means of these two experimental groups suggested that the effectiveness of resilience training on firefighters' self-efficacy improvement was higher than that of emotion regulation training. It should be noted that although all the training provided to firefighters during emotion regulation training sessions was effective in the improvement of their self-efficacy, resilience training addressed the issue of selfefficacy and how to improve it in a more specialized way over two sessions. This can justify the greater effectiveness of resilience training on promoting firefighters' self-efficacy compared to emotion regulation training.

In general, the results of the present study showed that resilience training and emotion regulation training have been effective on the psychological well-being and self-efficacy of firefighters in Ardabil. In addition, there was no significant difference between the effectiveness of the above two training methods on psychological well-being; however, resilience training was more effective than other methods on the improvement of self-efficacy.

\section{Suggestions and limitations}

Regarding the limitations of the present study, one can refer to the fact that although the self-reporting tools used in this study had appropriate validity and reliability, the answers to these scales may be somewhat affected by the social desirability or conditions of the subjects at the time of answering. Given the effectiveness of emotion-regulation training on the psychological well-being and self-efficacy of firefighters, it is recommended to use this training package along with other training to improve the mental health of firefighters. Eventually, resilience training and emotion-regulation training can be used interchangeably due to the same effect of these two methods on the psychological well-being and self-efficacy of firefighters.

\section{Ethical Considerations}

All procedures involving human participants in this study were performed in accordance with the ethical standards of the institutional research committee and the 1964 Helsinki declaration and its later amendments or comparable ethical standards. The participants were also assured of the confidentiality of their information. Moreover, the participation in the study was based on willingness and the participants were allowed to withdraw from the study at any time during the study.

\section{Funding/Support}

This study was supported by Vice Chancellor for Research in Mohaghegh Ardabili University (96.8.21.758).

\section{Authors' contributions}

The first author (Niloufar Sharifi) collected data and compiled the initial version of the article (50\%), the second author (Sajjad Basharpour) reviewed the original version and prepared the final version $(30 \%)$, and the third author (Mohammad Narimani) reviewed the final manuscript $(20 \%)$

\section{Conflicts of Interest}

The authors declare that they have no conflicts of interest regarding the publication of the study.

\section{References}

1. Meyer EC, Zimering R, Daly E, Knight J, Kamholz BW Gulliver SB. Predictors of posttraumatic stress disorder and other psychological symptoms in trauma-exposed firefighters. Psychological Services. 2012; 9(1):1-15. [DOI:10.1037/a0026414] [PMID]

2. Narimani $M$, Zahed A, Basharpour S. Prevalence of posttraumatic stress disorder in hospital emergency nurses and fire department workers in uremia city. Journal of Research in Behavioural Sciences. 2010; 8(1):69-74.

3. Akbari $M$. The role of personality traits and resiliency in prediction of nurses psychological well-being. International Journal of Behavioral Sciences. 2014; 7(4):307-13.

4. Luthans F, Youssef CM. Emerging positive organizational behavior. Journal of Management. 2007; 33(3):321-49. [DOl:10.1177/0149206307300814]

5. Regehr C. Crisis debriefing groups for emergency responders: Reviewing the evidence. Brief Treatment and Crisis Intervention. 2001; 1(2):87-100.

6. Mehrabian F, Kasmaei P, Atrkar RZ, Heidari M, Khalili RN. The effect of stress management education on firefighters' stress in Rasht. Iran Occupational Health Journal. 2017; 13(6):78-86.

7. Basharpour S. Personality traits: theory and testing. Tehran: Savalan Publications; 2016.

8. Behzadpour S, Motahari ZS, Vakili M, Sohrabi F. The effect of resilience training on increasing psychological well-being of infertile women. Journal of Ilam University of Medical Sciences. 2015; 23(5):131-42.

9. Momeni K, Jalili Z, Mohseni R, Karami J, Saeedi M, Ahmadi SM. Efficacy of teaching resiliency on symptoms reduction on anxiety of adolescence with heart disease. Journal of Clinical Research in Paramedical Sciences. 2015; 4(2):e81970.

10. Martin S, Fiske B, Lane S. Resilience-training for health care professionals. Journal of Obstetric, Gynaecologic \& Neonatal Nursing. 2019; 48(3):S94. [DOI:10.1016/j.jogn.2019.04.157]

11. NyklHček I, Vingerhoets A, Zeelenberg M. Emotion regulation and well-being: a view from different angles. Emotion regulation and well-being. New York: Springer; 2011.

12. Gratz KL, Gunderson JG. Preliminary data on an acceptance-based emotion regulation group intervention for deliberate self-harm among women with borderline 
personality disorder. Behavior Therapy. 2006; 37(1):25-35. [DOI:10.1016/j.beth.2005.03.002] [PMID]

13. Gross JJ, John OP. Individual differences in two emotion regulation processes: implications for affect, relationships, and well-being. Journal of Personality and Social Psychology. 2003; 85(2):348. [DOI:10.1037/0022 3514.85.2.348] [PMID]

14. Moradikia H, Arjmandnia AA, Ghobari Bonab B. Effectiveness of emotion regulation training on psychological well-being of Mothers of students with intellectual disability. Iranian Journal of Pediatric Nursing. 2016; 3(1):51-60. [DOI:10.21859/jpen-0301195]

15. Akhlaghi Yazdi Nejad F, Hossein Sabet F, Borjali A. Effectiveness of emotion regulation training on increasing self-efficacy and well-being in drug-dependent individuals. Journal of Occupational Health and Epidemiology. 2017; 6(1):9-16. [DOI:10.18869/acadpub.johe.6.1.9]

16. Cameron LD, Carroll P, Hamilton WK. Evaluation of an intervention promoting emotion regulation skills for adults with persisting distress due to adverse childhood experiences. Child Abuse \& Neglect. 2018; 79:423-33. [DOI:10.1016/j.chiabu.2018.03.002] [PMID]

17. Khanjani M, Shahidi S, Fath Abadi J, Mazaheri M, Shokri O. Factor structure and psychometric properties of short form (18 questions) Ryff Psychological Well-Being scale in male and female students. Thought and Behavior in Clinical Psychology. 2014; 8(32):27-36

18. Sherer M, Maddux JE, Mercandante B, Prentice-Dunn S, Jacobs B, Rogers RW. The self-efficacy scale: construction and validation. Psychological Reports. 1982; 51(2):663-71. [DOI:10.2466/pr0.1982.51.2.663]

19. Keramati H, Shahr-Arai MN. Investigating the relationship between self-perceived efficacy and performance on mathematics among junior high school students. Educational Innovations. 2004; 3(4):103-15

20. Dousti M, Pourmohamadreza Tajrishi M, Ghobari Bonab B. The effectiveness of resilience-training on psychological well-being of female street children with externalizing disorders. Scientific Journal Management System. 2014; 11(41):43-54

21. Wissing MP, Van Eeden C. Empirical clarification of the nature of psychological well-being. South African Journal of Psychology. 2002; 32(1):32-44.

22. Bandura A. Self-efficacy mechanism in psychobiologic functioning. Self-efficacy: Thought control of action. London: Hemisphere Publishing; 1992.

23. Ryff CD. Psychological well-being in adult life. Current Directions in Psychological Science. 1995; 4(4):99-104. [DOI:10.1111/1467-8721.ep10772395]

24. Ryff CD, Keyes CL, Hughes DL. Status inequalities, perceived discrimination, and eudaimonic well-being: Do the challenges of minority life hone purpose and growth? Journal of Health and Social Behavior. 2003; 44(3):275-91. [DOI:10.2307/1519779]

25. Foolad-chang, Hassan Nia. The effectiveness of emotion regulation training on happiness and self-efficacy of women heads of households. Journal of Women and Society. 2015 Feb 20; 5 (20): 89-106.

26. Choopan H, Kalantarkousheh SM, Aazami Y, Doostian Y, Farhoudian A, Massah O. Effectiveness of emotion regulation training on the reduction of craving in drug abusers. Addiction \& Health. 2016; 8(2):68-75. [PMID] [PMCID] 